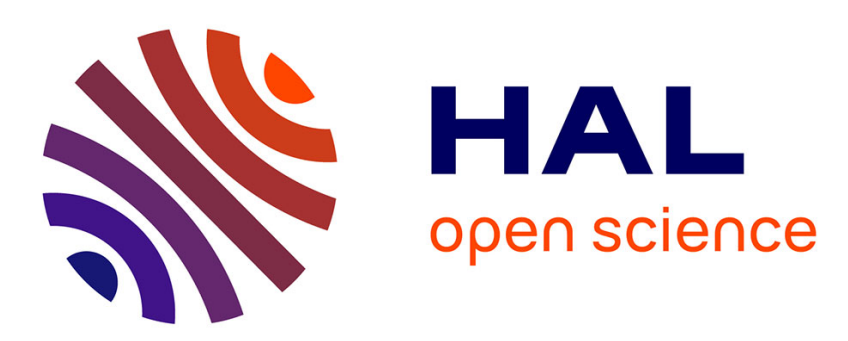

\title{
Small-group learning projects to make signal processing more appealing: From speech processing to OFDMA synchronization
}

Guillaume Ferré, Audrey Giremus, Eric Grivel

\section{- To cite this version:}

Guillaume Ferré, Audrey Giremus, Eric Grivel. Small-group learning projects to make signal processing more appealing: From speech processing to OFDMA synchronization. IEEE International Conference on Acoustics, Speech and Signal Processing, 2009. ICASSP 2009., Apr 2009, Taipei, Taiwan. pp.2317 - 2320. hal-00400717

\section{HAL Id: hal-00400717 https://hal.science/hal-00400717}

Submitted on 1 Jul 2009

HAL is a multi-disciplinary open access archive for the deposit and dissemination of scientific research documents, whether they are published or not. The documents may come from teaching and research institutions in France or abroad, or from public or private research centers.
L'archive ouverte pluridisciplinaire HAL, est destinée au dépôt et à la diffusion de documents scientifiques de niveau recherche, publiés ou non, émanant des établissements d'enseignement et de recherche français ou étrangers, des laboratoires publics ou privés. 


\title{
SMALL-GROUP LEARNING PROJECTS TO MAKE SIGNAL PROCESSING MORE APPEALING: FROM SPEECH PROCESSING TO OFDMA SYNCHRONIZATION
}

\author{
G. Ferré, A. Giremus and E. Grivel \\ Université de Bordeaux 1 - ENSEIRB \\ UMR 5218 IMS, 351 cours de la libération, 33405 Talence Cedex, France \\ Email : \{guillaume.ferre, audrey.giremus, eric.grivel\}@ims-bordeaux.fr
}

\begin{abstract}
Whereas lecturing is the most widely used mode of instruction, we have explored small-group learning projects to make signal processing more appealing at the University and in Engineering schools in Bordeaux (France). The projects cover a wide range of applications, from audio processing to mobile communication system analysis and can be based on problems suggested by industrial partners. After a state of the art in the area, the students develop signal processing algorithms and usually deliver new softwares. At the end of the semester, they provide a final 8-page report and present their work during a one-day workshop. The projects enable the students to experience cooperative works, which is mostly done in industry. In addition, they help the students to see more easily the links between the courses they follow, including project managing. The students are hence involved in dialog inside their own group, in writing English reports as well as in problem solving, analysis and synthesis. This paper presents four examples dealing with speech processing, spectral analysis, Universal Mobile Telecommunications System (UMTS) mobile positioning and orthogonal frequency division multiple access (OFDMA) synchronization.
\end{abstract}

Index Terms - orthogonal frequency-division multiple acces (OFDMA), UMTS, synchonization, localization.

\section{INTRODUCTION}

In France, teaching signal processing at the University or in the "Grandes Ecoles" national educative system ${ }^{1}$, usually consists of standard lectures with a few hours dedicated to exercises, laboratory sessions dealing with short practical examples and sometimes micro-projects. This organization enables the students to become familiar with the signal processing notions such as Fourier transform, Shannon theorem, digital filtering, etc. A personal involvement of the students is necessary for an effective learning. In addition, they often have the feeling that signal processing is nothing else but

\footnotetext{
${ }^{1} \mathrm{BAC}+4$ ou BAC +5 in France, the last year as a Bachelor and first year in MBA in the United Kingdom, in the US, etc.
}

mathematics. At that stage, despite the efforts teachers can make, the students do not necessarily see the connections between industry needs, job opportunities and their own curricula. They have to follow several other courses dedicated to mobile communication system, GPS navigation, biomedical applications and radar processing to understand how essential their skills in signal processing are. We have explored new vehicles to deliver educational content in signal processing:

- to make signal processing more appealing,

- to make the students more active and motivated,

- to help them see more easily the links between the various courses they follow,

- to enable them to experience cooperative works at least once before graduation.

Thus, for more than 7 years in Bordeaux, we have advocated small-group learning projects as a pedagogical approach to be used in conjunction with lectures for students in Master degree at the University or in an Engineering school. Students are working in small groups, i.e. 4 to 5 students and are usually supervised by two faculty members ${ }^{2}$. Involving students in decisions about their own curriculum improves student-performance areas such as autonomy and motivation. Therefore, numerous projects are presented each year to the students. The projects cover a wide range of applications, from GPS navigation issue and radar processing to mobile communication systems. Some may be two parts of a whole project or can start from works carried out the years before. The projects can also be based on problems suggested by industrial partners. Among the projects undertaken at the ENSEIRB $^{4}$ and at the university, here are some examples:

\footnotetext{
${ }^{2}$ We have encouraged projects supervised by two people for various reasons. Thus, when one of the supervisors is too busy, the other can replace him. The students can discuss with two people instead of one.

${ }^{4}$ ENSEIRB is a graduate school of engineering in electronics, computer science and telecommunications. The diploma of Engineering delivered at ENSEIRB corresponds to 5 years of higher education. Students are admitted to school following 2 years of preparation in higher education, through the selective national exams for the French grandes ecoles. The three other year course is designed to train top-level engineers in order to take positions in the field of electronics, computer science and telecommunications. There are 800 students and 250 diplomas of Engineering awarded each year.
} 
- Audio watermarking,

- Speech analysis for speech recognition,

- Speech enhancement using a single microphone,

- Spectral analysis for Dual Tone Multiple Frequency (DTMF) detection and classification,

- Rayleigh fading channel simulator,

- Receivers for MC-CDMA receivers,

- UMTS localization based on Kalman algorithms.

Then, the students rank them in order by preference. If there are more than five students interested in one project, they have to demonstrate their own motivations. In addition, the selection is made on the student curricula and the marks they obtained in the related courses ${ }^{3}$. The projects last one semester (12 to 14 weeks), 4 to 8 hours per week. The small group has to work on its own from one meeting to another. The students have specific tasks to enforce. They sometimes work alone or by pair. This depends on the work breakdown structure they choose.

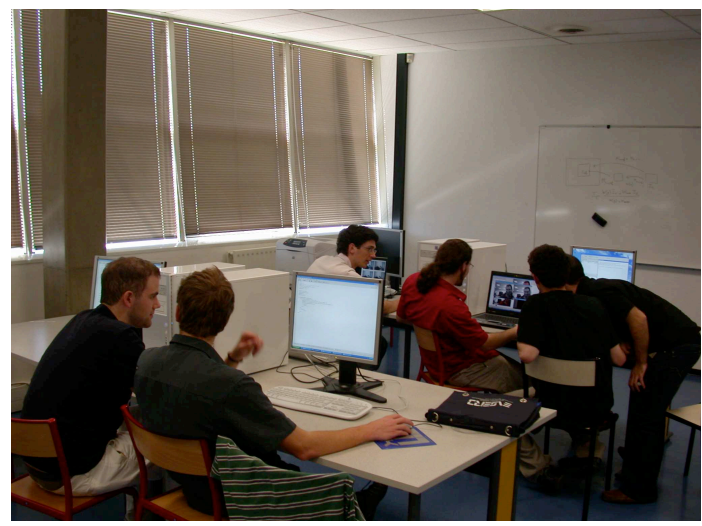

Fig. 1. students working either by 2 or 4

The project specifications are a priori defined, but the students are expected to suggest various technical solutions. Usually, the projects start by a state of the art (norms, technical reports, etc.) in the area. The students can hence search on the net or in the Library's electronic resources at the university. This task is useful to develop the ability of the students to extract, synthesize and use information from a variety of sources and media. In addition, letting them do their own research is always fruitful for the supervisors because the students do not necessarily find information where supervisors are used to looking at. After a few days, the small group and the supervisors exchange the reading packages or tips on how to find articles, books or items in a bibliography, during a meeting.

Usually, the students are asked to deliver new softwares or

\footnotetext{
${ }^{3}$ Thanks to the constructive feedbacks we received from the students during the first years, we have now defined these rules to avoid any problem concerning project assignment.
}

to create man machine interfaces using $\mathrm{C}$ language, Java or Matlab. They have to include the various steps of the proposed approaches (data loading, data plotting, processing, result analysis, etc.) and to provide guidelines. In addition, they can create websites to present their own works. In that case, they may have some exchanges with the network engineer. They are free to organize their ideas and to present their results on the websites. Self-organization is encouraged. The students can hence promote themselves to apply for a job or an internship. It should be noted that they usually have to prepare oral presentation and reports for supervisors or industrial partners. The student performance is evaluated by taking into account various qualifications such as general background knowledge, adaptability, readiness to learn, dependability, interpersonal skills, judgment, maturity, initiative, accuracy and flexibility. In addition, at the end of the semester, they provide a final 8-page report and present their work during a one-day workshop.

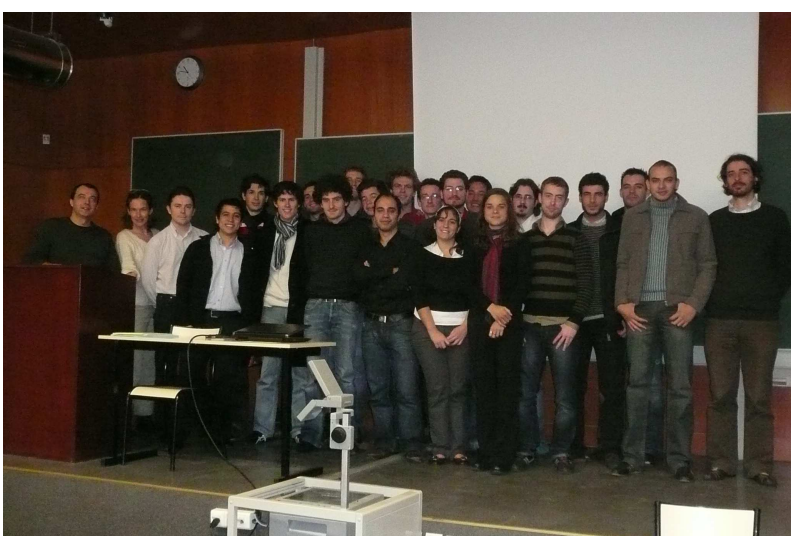

Fig. 2. some students and their supervisors during the oral presentation workshop

Remark: to carry out these projects, the only prerequisites are often the following:

- notions about random processes (wide sense stationnarity, ergodicity).

- basic knowledge in signal processing (correlation / covariance, Shannon theorem, Fast Fourier Transform, RIF/RII filtering and windowing).

The remainder of this paper presents four examples. The first application, speech and audio processing, is of great interest as the students do not need any a priori expertise to give their opinion. The two following cases deal with orthogonal frequency division multiple access (OFDMA) synchronization and Universal Mobile Telecommunications System (UMTS) mobile positioning. They make it possible to address parametric approaches, non-linear state space representation of a system, Extended Kalman filtering, etc. The last example is about spectral analysis and illustrates the collaboration with an industrial partner. 


\section{SPEECH AND AUDIO PROCESSING AS A STARTING POINT TO PROMOTE SIGNAL PROCESSING}

We often propose projects dealing with speech and audio processing to students who did not follow a large set of signal processing courses $(\mathrm{BAC}+4 /$ last year in the Bachelor degree). Speech and audio are appealing because the students are often familiar with these kinds of signals and have already manipulated them on their own with their MP3 reader or their computer. It is hence easy for them to see the direct applications of audio processing for coding and music mixes for instance. When using speech or audio, the students think they do not need to be experts to evaluate the algorithm performance. They always have an opinion when they listen to enhanced signals or signals after the coding-decoding system for instance. Therefore, these kinds of applications are very useful when the supervisors aim at promoting signal processing. As a starting point, the students can record their voices; they can watch the temporal representation of the signal and the corresponding spectrogram. In addition, they can easily disturb the signal by additive noise either white or colored and listen to them; then, they can design low-pass or band pass filters. At that stage, it can be of interest to show them that the only combination of basic notions such as windowing and FFT makes it possible to enhance a speech signal disturbed by an additive white noise, by using the short term spectral attenuation method [1]. They can also study subspace methods for speech enhancement [2]. This can be very fruitful if the students have followed a course dedicated to random process. In addition, the supervisor can introduce some advanced concepts such as parametric modelling (autoregressive parameters, reflexion coefficient, line spectrum pair -LSP-, immitance spectrum pair -ISP-), estimation techniques (least square criterion, etc.) and the connections between models and physical meanings. Norms such as [3] or speech enhancement combining AR modelling and Kalman filtering [4] can be also the basis of a project.

Remark: Psychoacoustic issues [5] can be addressed. More particularly, the human auditory system such as the simultaneous masking, Johnstons method [6] and the psychoacoustic model of MPEG 1 Layer 1 can be implemented. This can be a complementary study for audio coding or algorithms that can be taken into account for speech enhancement [7].

\section{UMTS BASED MOBILE POSITIONING AND OFDMA SYNCHRONIZATION: TWO APPLICATIONS TO DEAL WITH NON LINEAR PARAMETRIC APPROACHES}

Our goal is to illustrate the signal processing techniques seen in lectures, through recent communication applications.

Indeed the common feature of many current wireless stan- dards is to increase the transmission rate to propose more and more new services. Thus, orthogonal frequency division multiple access (OFDMA), is becoming the prefered system for many new high data rate wireless communication standards. In addition among all the new services, localization is being paid a lot of attention.

As the students feel very concerned with these new applications, it is easier to present these concepts and notions that are not necessarily easy to teach during a lecture. Thus, nonlinear state space representation of a system and Extended Kalman filtering (EKF) can be addressed, through the two following examples: UMTS-based localization and uplink WiMax waveform synchronization.

The first proposed project focuses on localization solutions based on cellular phone technology, specifically UMTS phones. Actually, this technology is a sufficient and attractive option in terms of coverage and accuracy for a wide range of indoor, outdoor, and place based location-aware applications. The solutions are simulated from a user interface which provides the results of UMTS localization. During this project, some methods have been proposed to estimate the location of an UMTS mobile phone using two kinds of measurements: time of arrival (TOA) or angle of arrival (AOA). Students addressed two major phenomena: additive noise and non line of sight (NLOS). They override them by using either a LeastSquares (LS) method or a Kalman filter to mitigate noise effects, and a bias detection algorithm for the NLOS situations. The results are kind of satisfying, but the simulated localization scenario remains simple: for instance, only one measurement is assumed in NLOS at a time. Nevertheless this work will be used as a basis for future projects with others students.

The second proposed project is about synchronization problems in OFDMA uplink systems. Due to the bandlimitation of a wireless communication channel, another interesting field concerns the frequency allocation optimization. The current trend consists of using a modulation scheme known as OFDMA. In OFDMA, different users simultaneously transmit their own data by modulating an exclusive set of orthogonal subcarriers. This allows one to easily recover each user signal at the receiver. Moreover, this technique makes it possible to reduce inter channel interference (ICI), has a better spectral efficiency and is able to cope with channel distortions. As a drawback, its level of performance is very sensitive to synchronization errors: timing and carrier frequency offsets (CFO). Three methods are proposed to estimate CFO based on the uplink retransmission of data symbols. A first synchronization technique is based on Maximum Likelihood Estimator (MLE) while a second uses a linearization to apply the LS algorithm. Finally, to improve the throughput of these first two procedures, an EKF method has been proposed. They have been implemented by supposing known the propagation channel.

Like the UMTS based project, this study would be used as a basis to complete the synchronization algorithm with 
the channel estimation. This part attempts to implement the channel and the CFO estimation at the receiver side to build an OFDMA system able to work in a typical cellular mobile communication channel.

\section{SPECTRAL ANALYSIS FOR VIBRATORY SIGNALS, WITH AN INDUSTRIAL PARTNER}

Proposing a small-group project in collaboration with an industrial partner is always interesting either for the students, the project supervisors or the industrial partner. In this way, the students have the opportunity to discuss with engineers. They have hence contacts with the end users. Meetings can be organized either at school or in the company. This can be an incentive for students to feel more concerned and involved by the project. For the industrial partner and the supervisors, this project can be the basis of proactive discussions between an industrial and an academic scientist. This participates in the emergence of new types of relationship between industry and academic stuffs. Among the proposed subjects, we present in this section one dedicated to spectral analysis for vibratory signals. In that case, the students have to carry out a comparative study between various spectral analysis methods. One can start by implementing standard approaches such as periodograms and correlograms or Capons method. In addition, parametric methods can be studied such as those based on AR approaches. In that case, the estimations of the AR parameters can be addressed by means of the standard YuleWalker equations. Maximum Entropy (ME) Burgs and autocovariance method can be also considered. The influence of the additive measurement noise, assumed to be white, can be also considered and is an opportunity for the supervisor to suggest the use of alternative approaches such as the Least Square Yule-Walker (LSYW), the Total Least Square YuleWalker (TLSYW). One can also look at the truncated SVD approach which is based on the SVD of the observation autocorrelation matrix. If the students have followed a course dedicated to random processes, high resolution spectral analysis such as ESPRIT and MUSIC can be also implemented.

\section{STUDENT COMMENTS}

We are accustomed to asking for a student feedback about the lectures and the projects. In this section, we present some student comments. F. Faurie (currently PhD student) and A. Ferrer (currently enginneer in Sofrelog) give respectively their opinion about UMTS and OFDMA projects.

"I have worked on UMTS localization during the project. It was a good initiation to the research. I could discover the bibliographic aspect of this work, but also the programming one to validate our theoretical approaches. It gave me the opportunity to work in team. Furthermore, it offered us the time to work on our own and to work deeper on a specific project." F. Faurie.

"Projects allow students to work in team during long periods on specific subjects. As a consequence, students can better understand how the different technics studied in class are used in concrete applications. Thanks to these projects, students get the opportunity to step back on their knowledge and build real experiences, which is primary to enrich one's resume and find good internships." A. Ferrer.

\section{CONCLUSIONS}

In this paper, we have reported the kind of projects and pedagogical methods we use to make signal processing more appealing. The main advantage of such projects is that the students have to work like professional engineers. They are involved in dialog, in debate inside their own group, in writing English reports, in problem solving, analysis, synthesis and evaluation.

\section{REFERENCES}

[1] S.F. Boll, "Suppression of acoustic noise in speech using spectral subtraction," IEEE Trans. on Acous-tics, Speech and Signal Processing, vol. 27, no. 2, pp. 113-120, April 1979.

[2] P.C. Hansen S.D. Hansen, S.H. Jensen and J. Sorensen, "A signal subspace approach for noise reduction of speech signals," Proc. of EURASIP-EUSIPCO '94, Edinburgh, Scotland, pp. 1174-1177, September 1994.

[3] IUT-T Rec. G729, "Coding of speech at $8 \mathrm{kbit} / \mathrm{s}$ using conjugate structure algebraic-code-excited linear prediction (cs-acelp)," http://www.itu.int/rec/T-REC-G.729/e.

[4] K.K. Paliwal and A. Basu, "A speech enhancement method based on kalman filtering," in Proc. of IEEEICASSP '87, Dallas, USA, pp. 177-180, 1987.

[5] E. Zwicker and H. Fastl, Psychoacoustics, Facts and model, Springer Verlag, second updated edition edition, 1999.

[6] J.D. Johnston, "Transform coding of audio signals using perceptual noise criteria," IEEE Journal on Selected Areas in Communications, vol. 6, no. 2, pp. 314-323, February 1988.

[7] N. Ma M. Bouchard and R.A. Goubran, "Speech enhancement using a masking threshold constrained kalman filter and its heuristic implementations," IEEE Trans. on Audio, Speech and Language Processing, vol. 14, no. 1, January 2006. 